\title{
Epithelial Notch signaling is a limiting step for pancreatic carcinogenesis
}

\author{
Marsha M Thomas', Yaqing Zhang ${ }^{1}$, Esha Mathew ${ }^{2}$, Kevin T Kane ${ }^{1}$, Ivan Maillard ${ }^{2,3}$ and Marina Pasca di Magliano ${ }^{1,2,4^{*}}$
}

\begin{abstract}
Background: Pancreatic cancer is one of the deadliest human malignancies, with few therapeutic options. Re-activation of embryonic signaling pathways is commonly in human pancreatic cancer and provided rationale to explore inhibition of these pathways therapeutically. Notch signaling is important during pancreatic development, and it is re-activated in pancreatic cancer. The functional role of Notch signaling during pancreatic carcinogenesis has been previously characterized using both genetic and drug-based approaches. However, contrasting findings were reported based on the study design. In fact, Notch signaling has been proposed to act as tumor-promoter or tumor-suppressor. Given the availability of Notch inhibitors in the clinic, understanding how this signaling pathway contributes to pancreatic carcinogenesis has important therapeutic implications. Here, we interrogated the role of Notch signaling specifically in the epithelial compartment of the pancreas, in the context of a genetically engineered mouse model of pancreatic cancer.

Methods: To inhibit Notch signaling in the pancreas epithelium, we crossed a mouse model of pancreatic cancer based on pancreas-specific expression of mutant Kras with a transgenic mouse that conditionally expresses a dominant negative form of the Mastermind-like 1 gene. MAML is an essential co-activator of the canonical Notch signaling-mediated transcription. DNMAML encodes a truncated MAML protein that represses all canonical Notch mediated transcription in a cell autonomous manner, independent of which Notch receptor is activated. As a result, in mice co-expressing mutant Kras and DNMAML, Notch signaling is inhibited specifically in the epithelium upon Cre-mediated recombination. We explored the effect of epithelial-specific DNMAML expression on Kras-driven carcinogenesis both during normal aging and following the induction of acute pancreatitis.

Results: We find that DNMAML expression efficiently inhibits epithelial Notch signaling and delays PanIN formation. However, over time, loss of Notch inhibition allows PanIN formation and progression.

Conclusions: Epithelial-specific Notch signaling is important for PanIN initiation. Our findings indicate that PanIN formation can only occur upon loss of epithelial Notch inhibition, thus supporting an essential role of this signaling pathway during pancreatic carcinogenesis.
\end{abstract}

Keywords: Pancreatic cancer, Notch, DNMAML, Mastermind-like, Epithelium, Genetically engineered mouse model

\section{Background}

Pancreatic ductal adenocarcinoma (PDA), the most common form of pancreatic cancer, is a highly aggressive malignant disease with a very poor prognosis. It is the fourth most common cause of cancer-related mortality across the US and other developed countries independent of

\footnotetext{
* Correspondence: marinapa@umich.edu

'Department of Surgery, 1500 E Medical Center Drive, Ann Arbor, Michigan 48109-5936, USA

${ }^{2}$ Cell and Molecular Biology Program, University of Michigan, 2966 Taubman Medical Library, Ann Arbor, Ml 48109-0619, USA

Full list of author information is available at the end of the article
}

race or sex, as the number of new cases and diseaserelated deaths are roughly equal $[1,2]$. There is a dire need for new therapeutic options for this disease to increase the dismal 5-year survival, which is currently less than $5 \%$.

PDA develops through a series of non-invasive precursor lesions, the most common of which are pancreatic intraepithelial neoplasia or PanINs [3]. Oncogenic mutations in KRAS are widespread in human PanINs and detected in in over 90\% of human PDA [3-6]. In addition, PanIN progression is marked by aberrant activation of 
embryonic signaling pathways, like Hedgehog, Wnt, and Notch [3-5,7-9]. Expression of oncogenic Kras in genetically engineered mice recapitulates the step-wise progression of the human disease, and gives rise to one of the most commonly used mouse models of pancreatic cancer, the KC mouse [4].

Notch signaling induces the expansion and transformation of an undifferentiated precursor population during pancreatic cancer progression [9-13]. Extensive analysis of human pancreatic cancer revealed activation of Notch signaling both in PanINs and in PDA $[4,9]$. Notch has been shown to be important for stimulating proliferation in transformed cells [10]. A recent study used a $\gamma$-secretase inhibitor (GSI) to block Notch signaling in KPC mice [10], resulting in reduced incidence of PanIN lesions and decreased proliferation of PanINs. These studies and others imply Notch signaling may regulate proliferation of transformed acinar-ducal metaplasia (ADM) structures and PanINs [10]. Nevertheless, GSIs could block other functions in the cell other than Notch signaling, since $\gamma$ secretase targets other proteins in addition to Notch components [14]. Furthermore, GSIs systemically blocks all Notch activity independent of cell types, making it difficult to tease apart the details of Notch signaling in pancreatic cancer cells versus effects on the stroma [14].

Several studies have used genetic approaches to ablate individual Notch receptors and study the effect on pancreatic carcinogenesis. Interestingly, these experiments resulted in contrasting findings depending on the specific Notch receptor being targeted, with either tumor suppressive or tumor promoting effects being observed [10,12,13,15-17]. Thus, a study addressing complete ablation of Notch signaling in the pancreatic epithelium in $\mathrm{KC}$ mice was so far missing.

Here, we report the use of a dominant negative form of MAML1 (DNMAML), a critical regulator of canonical Notch activity, to address the requirement of Notch signaling within the tumor epithelium during pancreatic tumorigenesis [18].

\section{Methods}

\section{Mouse strains}

Animals were housed in pathogen-free conditions and maintained in facilities of the University of Michigan Comprehensive Cancer Center and this study was included in our animal use protocol, approved by the University of Michigan University Committee on Use and Care of Animals (UCUCA). P48-Cre (Ptfla-Cre) [19] (provided by Christopher V. Wright, Vanderbilt University, Nashville, Tennessee, USA) and LSL-Kras ${ }^{\text {G12D }}$ [20] (provided by David Tuveson, Cambridge Research Institute, Cambridge, United Kingdom) were crossed to generate $\mathrm{KC}$ mice, as previously described $[4,20]$. ROSA $A^{D N M A M L /+}$ mice $[21,22]$ were crossed with $\mathrm{KC}$ mice to generate $\mathrm{KC}$;
DNMAML mice. Wild type mice and animals having a combination of Kras allele and/or DNMAML, but not the Cre allele were used as controls. Allele-specific PCR on mouse tail DNA, was used to verify the presence of each allele. DNMAML induction was monitored through GFP expression in pancreas epithelium. 5 animals per cohort ( $\geq 5$ mice/cohort) were aged 15 and 26 weeks before euthanasia. Tissues were collected for histopathological analysis.

\section{Genotyping}

Tail DNA was extracted using hot sodium hydroxide and tris (HotSHOT) DNA extraction protocol, as previously described [23]. The primers used for p48-Cre, $\operatorname{Kras}^{G 12 D}$, and ROSA ${ }^{D N M A M L /+}$ were as follows: p48-Cre, 5'-catgcttcatcgtcggtcc- 3' (forward) and 5'-gatcatcagcta caccagag-3' (reverse); Kras ${ }^{G 12 D}$, 5'-agctagccaccatgagtaa gtctgca-3' (forward) and 5'-cctttacaagcgccgcagactgtaga-3' (reverse); Rosa ${ }^{\text {DNMAML-GFP/+ }}$, 5'-aaagtcgctctgagttgttat-3' (Rosa1), 5'-gcgaagagtttgtcctcaacc-3' (Rosa2), and 5'-gga gcgggagaaatggatatg-3' (Rosa3). PCR cycling conditions were as follows: p48-Cre, Kras ${ }^{\mathrm{G} 12 \mathrm{D}}, 95^{\circ} \mathrm{C}$ for $3 \mathrm{~min}, 95^{\circ} \mathrm{C}$ for $30 \mathrm{~s}, 60^{\circ} \mathrm{C}$ for $30 \mathrm{~s}$, and $72^{\circ} \mathrm{C}$ for $45 \mathrm{~s}$ for 34 cycles, followed by $72^{\circ} \mathrm{C}$ for $5 \mathrm{~min}$; Rosa ${ }^{\mathrm{DNMAML}-\mathrm{GFP} /+}, 95^{\circ} \mathrm{C}$ for $3 \mathrm{~min}, 95^{\circ} \mathrm{C}$ for $30 \mathrm{~s}, 59^{\circ} \mathrm{C}$ for $30 \mathrm{~s}$, and $72^{\circ} \mathrm{C}$ for $1 \mathrm{~min}$ for 34 cycles, followed by $72^{\circ} \mathrm{C}$ for $5 \mathrm{~min}$. Amplified PCR products were run on $2 \%$ agarose gels with molecular weight markers. PCR products were visualized under Alpha Innotech UV transilluminator.

\section{Induction of acute pancreatitis}

Animals were administered caerulein (Sigma-Aldrich) by intraperitoneal injections in two series of 8 hourly at a concentration of $75 \mu \mathrm{g} / \mathrm{kg}$ over a 48 hour period, as previously described [24]. Age-matched controls were injected in parallel with experimental mice.

\section{Immunohistochemistry and immunofluorescence}

Pancreatic tissues from experimental and control mice were dissected and fixed overnight in 10\% neutralbuffered formalin (Fisher Scientific) embedded in paraffin and sectioned $(4-5 \mu \mathrm{m})$. The University of Michigan Cancer Center Histopathology Core performed all embedding and sectioning. Paraffin-embedded tissue sections were processed using $2 \times$ xylene for $5 \mathrm{~min}, 2 \times$ $100 \%$ ethanol for $5 \mathrm{~min}, 2 \times 95 \%$ ethanol for $2 \mathrm{~min}$, and rinsed under running deionized water for $5 \mathrm{~min}$. Antigen retrieval was performed using citrate buffer (BioGeneX) in the microwave and cooled. Blocking of endogenous peroxidase activity was achieved using 3\% hydrogen peroxide for $10 \mathrm{~min}$, and then sections were blocked using 5\% albumin from bovine serum (BSA; Sigma-Aldrich) for 30 min. Hematoxylin/Eosin (H\&E), Periodic Acid Staining (PAS), Gomori trichrome, and immunohistochemistry 
staining was performed as previously described [5]. For a list of antibodies used, see Additional file 1: Table S1. Images were taken with an Olympus BX-51 microscope, Olympus DP71 digital camera, and DP Controller software.

For immunofluorescence, secondary-antibodies labeled with Alexa Fluor 488 (Life Technologies). Cell nuclei were counterstained with 4,6-diamidino-2-phenylindole (DAPI; Invitrogen). The immunofluorescent images were acquired using an Olympus IX-71 confocal microscope and FluroView FV500/IX software.

\section{Hes1 staining}

Paraffin-embedded tissue sections were processed as described. Hes 1 antibody (a gift from Ben Stanger, University of Pennsylvania, Philadelphia, PA, USA) at a 1:1500 dilution was amplified using Tyramide Signal Amplification system (PerkinElmer). Alexa Fluor 5. was used to visualize staining by immunofluorescence (Life Technologies).

\section{Quantitative real time PCR}

Tissue for RNA extraction was stabilized through overnight incubation in RNAlater-ICE (Ambion) at $-20^{\circ} \mathrm{C}$, then isolated using RNeasy Mini Kit (QIAGEN) according to manufacturer's instructions. Reverse transcription reactions were conducted using a High-Capacity cDNA Reverse Transcription Kit (Applied Biosystems). Samples for quantitative RT-PCR were prepared with $1 \times$ Power SYBR Green PCR Master Mix (Applied Biosystems) and various primers (Additional file 1: Table S2). All primers were optimized for amplification under reaction conditions as follows: $95^{\circ} \mathrm{C}$ for $10 \mathrm{~min}$, followed by 40 cycles of $95^{\circ} \mathrm{C}$ for $15 \mathrm{~s}$ and $60^{\circ} \mathrm{C}$ for $1 \mathrm{~min}$. Melting curve analysis was performed for all samples after completion of the amplification protocol. Cyclophilin and Gapdh were used as the reference gene expression controls. Hes1 primers were acquired from Applied Biosystems; Mouse Hes1 (Mm01342805_m1), Mouse Gapdh (Mm99999915_g1). Amplification was preformed using the StepOnePlus System (Applied Biosystems), and experiments were performed in triplicates. The results were calculated following the $2 \Delta C_{p}$ method using the StepOne Software (Applied Biosystems). A two-tailed unpaired t test was used for statistical analysis.

\section{Histopathological analysis}

The histopathological analysis was performed as previously described [25]. In brief, 5 randomly selected, nonoverlapping high-power images $(20 \times$ objective) were taken for each slide. A minimum of 50 total acinar or ductal clusters was counted from at least three independent animals for each group. Each cluster counted was classified as acinar, ADM, PanIN1A, PanIN1B, PanIN2, and PanIN3 based on the classification consensus [26]. Prism software was used to perform statistical tests and assess statistical significance. (GraphPad; Mac version 6.0). A $P$ values were calculated according to multiple $t$ test and were considered significant when less than 0.05 and highly significant when less than 0.01 .

\section{Results}

\section{Epithelial-specific inhibition of Notch signaling}

To block Notch signaling during pancreatic carcinogenesis, we crossed a mouse model of pancreatic cancer, based on pancreas-specific expression of mutant Kras (p48-Cre; LSL-Kras ${ }^{\mathrm{G} 12 \mathrm{D}}$; hereby referred to as KC) with a transgene expressing a Dominant-Negative form of Mastermind-like1 (DNMAML), which encodes for a truncated form of MAML1 (aa 13-74) fused to GFP, downstream of a LoxP-flanked stop cassette [5,6,21] (Figure 1D). The DNMAML-GFP fusion product is a potent inhibitor of Notch 1-4 signaling in vivo and in vitro and interferes with the NICD-CSL/RBPJ-MAML complex formation, which is essential for transcriptional activation of Notch target genes in a cell autonomous manner [18,27] (Figure 1A). The DNMAML-GFP allows tracking recombination events in individual cells by taking advantage of the GFP fusion protein [21].

To verify the ability of DNMAML to inhibit Notch signaling in the pancreas, we harvested pancreata from 15 week old wild type, $\mathrm{KC}$, and $\mathrm{KC}$;DNMAML mice and analyzed the expression of Notch target genes in wholetissue mRNA (5 mice/cohort). Expression of Hes1, Hey1, and Hey2, common targets of Notch signaling was assessed by quantitative real time polymerase chain reaction (RT-qPCR) [28-30] (Figure 1B). We observed elevated levels of Hes1, Hey1, and Hey2 in KC mice compared to WT control samples, in accordance with previously published data showing Notch signaling upregulation in PanINs and PDA $[4,9,10]$. Importantly, the Notch target genes were downregulated in KC;DNMAML mice compared to KC. Thus, DNMAML expression successfully inhibited Notch signaling in the pancreas in vivo.

\section{Epithelial Notch signaling is important for PanIN initiation} In order to determine the effects of Notch inhibition in the epithelial compartment during pancreatic carcinogenesis, we harvested tissue from age-matched $\mathrm{KC}$ and KC-DNMAML mice at $15(\mathrm{n}=5)$ and $26(\mathrm{n}=28)$ weeks of age and examined tissue histology for neoplastic progression. In 15 week-old samples we observed a significant reduction in the number of PanINs in KC;DNMAML mice compared to $\mathrm{KC}$ mice (Figure 1E). Thus, inhibition of Notch signaling delayed or blocked PanIN formation. Analysis of those PanINs that were present in $\mathrm{KC}$; DNMAML mice did not reveal any significant histological difference compared to PanINs in KC mice. Then, we examined the pancreata of KC;DNMAML and $\mathrm{KC}$ mice dissected at 26 weeks of age (Figure 1F). At this time point, 


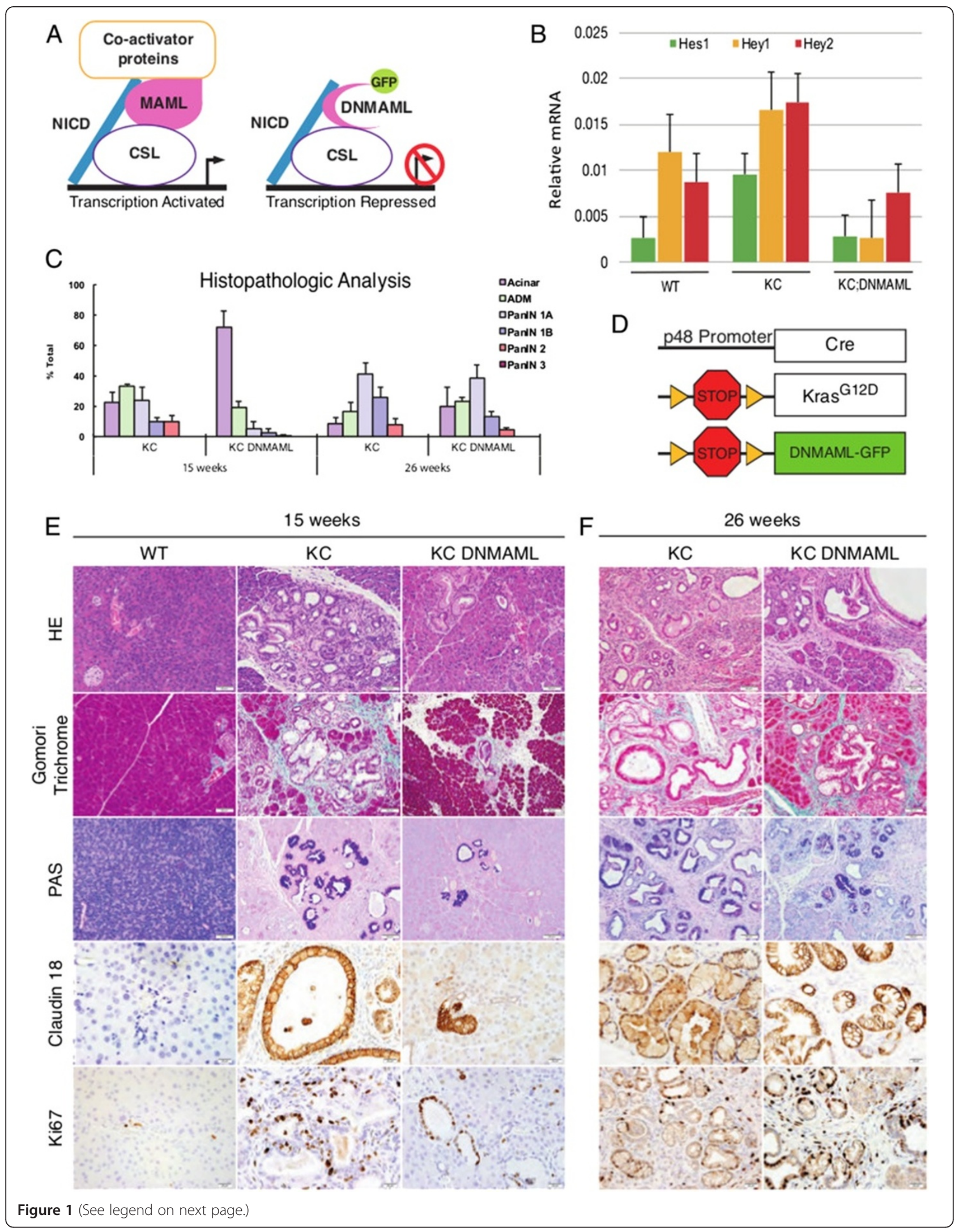


(See figure on previous page.)

Figure 1 Epithelial-specific inhibition of Notch signaling in DNMAML model. (A) Scheme of DMAML-mediated inhibition of Notch signaling. The Notch intracellular domain (NICD; blue) forms a complex with suppressor of hairless and lag-1 (CSL; purple lined), Mastermind-like1 (MAML; pink), and co-activators (yellow lined), to activate transcription of Notch target genes. The DNMAML-GFP fusion protein blocks formation of the activation complex, thus preventing transcription of the target genes. (B) Pancreata from 15 week-old wild type (WT), p48Cre; LSL-KrasG12D (KC), and p48Cre;LSL- KrasG12D mice (KC;DNMAML) were analyzed for the expression of common Notch target genes, Hes1 (green column), Hey1 (yellow column) and Hey2 (red column) by qRT-qPCR. The expression levels were normalized to Gapdh. Data represent mean \pm SEM. (C) Quantification of pancreatic intraepithelial neoplasia (PanIN) of age-matched KC and KC;DNMAML mice ( $n=3-5$ mice/genotype). Color-coding: acini (dark purple), acinar-ductal metaplasia (ADM; green), PanIN1A (light blue), PanIN2B (blue), PanIN2 (red), PanIN3 (dark red). Data represent mean \pm SEM. The statistical difference was determined by two-tailed Student t-test. ${ }^{*} \mathrm{p}<0.05$, ${ }^{* *} \mathrm{p}<0.0001$. (D) Genetic makeup of KC;DNMAML mice. (E) Analysis of 15-week old mice. H\&E staining (20x); collagen deposition (Gomori Trichrome; 20x); mucin accumulation (Periodic Acid Staining; PAS; 20x); a PanIN-specific marker (Claudin18; 40x), and proliferation (Ki67; 40x). (F) Analysis of 26-week old mice.

there was no significant difference in the number of PanINs between KC and KC;DNMAML mice. There results were consistent with Notch inhibition being insufficient to block PanIN formation, or with loss of Notch inhibition through a negative selection process. We performed histological and molecular analysis of PanINs in $\mathrm{KC}$ and KC;DNMAML tissues. PanIN lesions from both genotypes expressed typical markers such as Claudin18 and showed intracellular mucin staining (PAS staining), in addition to collagen deposition (Gomori Trichrome staining). To compare the proliferation index among the two genotypes, we performed Ki67 staining [31]. At 15 weeks and 26 weeks, we observed elevated Ki67 staining in both the tumor epithelium and stromal compartment, independent of genotype (Figure 1E,F). We then analyzed apoptosis, by cleaved Caspase 3 staining and did not observe any difference in the two sets of mice (data not shown). Thus, once PanINs had formed, they had the expected proliferation and cell survival rate.

Histopathological analysis of de-identified slides confirmed our initial observations. Namely, KC;DNMAML samples had more acinar clusters compared to KC samples (80\% and 30\% respectively) and less ADM (20\% and $35 \%$, respectively) at 15 weeks. $\mathrm{KC}$ pancreata displayed a greater degree of disease progression with a higher proportion of PanIN1A (20\%), PanIN1B (8\%), and PanIN2 (1\%) compared to age-matched KC;DNMAML mice (Figure 1C). At 26 weeks, we observed significantly fewer PanINs and more acini in KC;DNMAML mice compared to KC. Moreover, KC;DNMAML had lower-grade PanINs than $\mathrm{KC}$ samples, reflecting the delay in lesion onset (Figure 1C). Thus, PanINs were delayed, but their formation was not blocked, upon inhibition of epithelial Notch signaling. This finding might be explained by progressive loss of Notch-dependency (possibly due to compensation by other signaling pathways) or by loss of Notch inhibition due to competitive disadvantage -thus eliminationof DNMAML expressing cells.

In order to determine whether DNMAML expression had been lost over time, or whether Notch signaling was still inhibited in the epithelial compartment, we analyzed Hes1 and GFP protein localization by immunofluorescence
(Figure 2). At 15 weeks, Hes1 was upregulated in $\mathrm{KC}$ samples but not in KC-DNMAML tissues as predicted. GFP staining overlapped with DAPI nuclear staining, suggesting that DNMAML was localized in the nuclear compartment (Figure 2A and C). At 26 weeks, Hes1 appeared further upregulated in $\mathrm{KC}$ samples, and we also observed Hes1 expression in the PanINs of KC-DNMAML tissues, suggesting increased Notch activity (Figure 2B and C). Moreover, we observed loss of nuclear GFP, and concurrent appearance of cytoplasmic or membrane GFP. While we can't fully explain the mechanism underlying the latter finding, we nevertheless were able to conclude that the DNMAML-mediated inhibition of Notch signaling was lost over time, either by loss of DNMAML expression or DNMAML-expressing cells, or by inappropriate subcellular localization of the DNMAML-GFP fusion protein. Thus, the loss of phenotype in KC;DNMAML mice over time coincided with re-activation of Notch signaling. These data thus support an essential requirement for epithelial Nocth signaling during PanIN formation.

To further our analysis of KC;DNMAML mice, we investigated whether inhibition of Notch signaling affected the activation of other embryonic signaling pathways that are upregulated in PanIN formation and important for their progression, such as Hedgehog and Wnt [5,8,32-35]. Thus, we harvested tissue from 15 and 26 week old $\mathrm{KC}$; DNMAML and age-matched $\mathrm{KC}$ mice and extracted mRNA to analyze Hedgehog and Wnt associated gene expression, such as Patched-1 (Ptch1), a Hedgehog pathway component and target gene, and Wnt3a (Wnt3a), a Wnt ligand [5,8] (Figure 2D).

In the same set of experiments, we measured Hes1 expression by qPCR, to determine the degree of Notch inhibition in the individual samples (Figure 2D). At 15 weeks, we observed a trend towards a decrease in HES1 in $\mathrm{KC}$ DNMAML samples ( $\mathrm{n} \geq 3$ ) when compared to KC samples, as predicted. Our data did not reach statistical significance, possibly due to the heterogeneous nature of whole tissue samples. At 26 weeks, there was no difference in HES1 expression between KC and KC-DNMAML samples, corroborating our immunostaining-based results described above. At neither time point did we observe a 


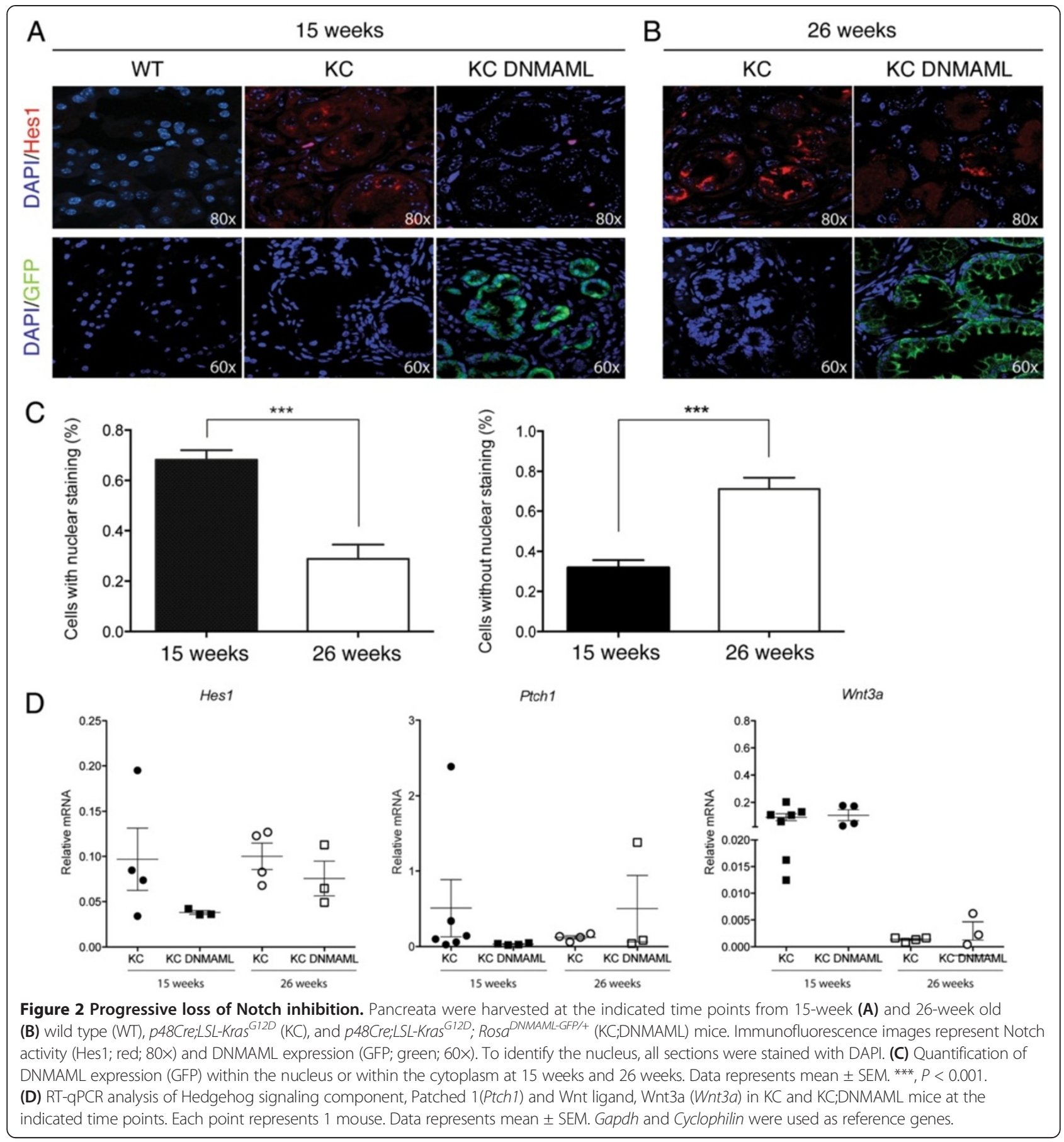

difference in Ptch-1 and Wnt3a expression. Thus, inhibiting Notch signaling had no effect on Hedgehog and Wnt activity.

To complement the qPCR-based experiments, we analyzed the expression of downstream effectors of Kras, Hedgehog, and Wnt signaling by immunostaining (Figure 3). To analyze the activity of Kras effector pathways, we performed immunostaining for AKT and MAPK signaling components (ERK). Immunostaining of the activated form of ERK and AKT (phospho-ERK1/2 and phospho-AKT) at 15 and 26 weeks revealed elevated p-ERK and p-AKT in PanINs, independent of genotype. While we did not observe changes in Kras effector pathways, the progressive loss of Notch inhibition in our model does not allow a rigorous epistatic analysis of these pathways.

To examine whether Notch inhibition in the tumor epithelium affected the expression of Hedgehog ligands, 


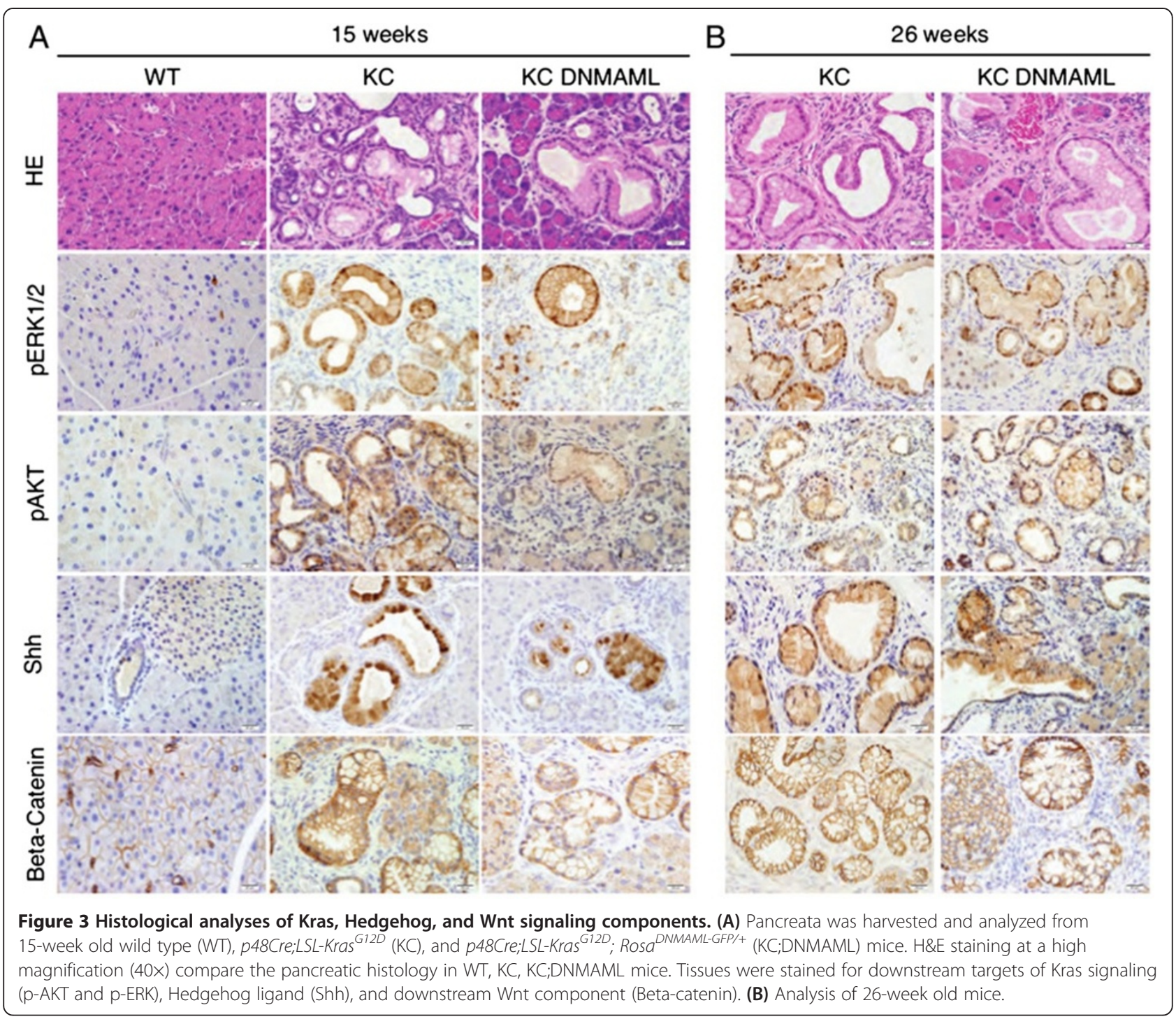

we performed immunostaining against Sonic Hedgehog (Shh). Shh is commonly upregulated in PanIN lesions $[5,32,33,36]$. Studies have shown that upregulation of Hedgehog signaling promotes tumorigenesis $[5,32,33,36]$. We detected Shh in the PanIN epithelium and not in the surrounding stroma, in both $\mathrm{KC}$ and KC-DNMAML; thus the expression of the Hedgehog pathway ligand Shh was not regulated by Notch signaling. To assess Wnt signaling activity in vivo, we performed immunostaining against beta-catenin. We did not observe changes in expression or subcellular localization of beta-catenin in the PanIN epithelium comparing $\mathrm{KC}$ and KC-DNMAML mice.

\section{Determining the requirement of Notch signaling during pancreatitis-driven PanIN formation}

In our previous set of experiments, $\mathrm{KC}$ and $\mathrm{KC}$; DNMAML mice developed PanINs spontaneously, over time. Several studies have reported that, in mice, the induction of acute pancreatitis synergizes with oncogenic Kras to induce rapid and extensive PanIN formation [6,24,37-39]. To investigate the potential requirement for active Notch signaling during pancreatitis-induced carcinogenesis, we administered a cholecystokinin (CCK) agonist (caerulein), which induces acute pancreatitis in mice (8 injections/day; 2 day treatment). We collected tissues from age-matched wild type (control), $\mathrm{KC}$, and KC;DNMAML mice 2, 3, and 4 weeks following acute pancreatitis (Figure 4A). Acute pancreatitis leads to acinar damage, mainly represented by ADM, edema of the tissue, and infiltration of inflammatory cells both in WT and $\mathrm{KC}$ mice. However, while WT mice rapidly recover, with complete tissue repair usually observed within a week, $\mathrm{KC}$ mice are unable to undergo tissue repair (Figure 4B). In contrast, in $\mathrm{KC}$ mice, the pancreas becomes progressively fibrotic and the ADM becomes more extensive 


\section{A}
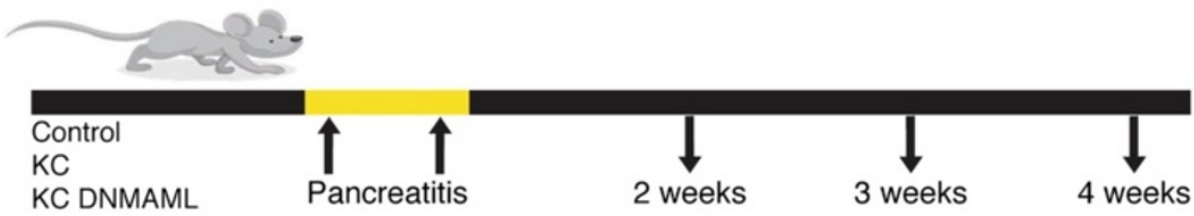

B
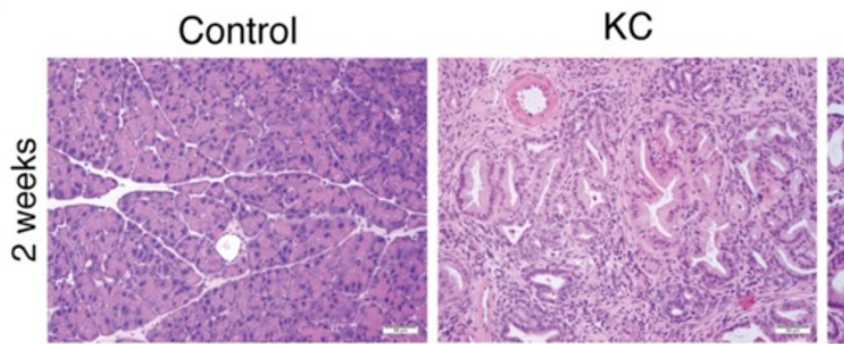

KC DNMAML
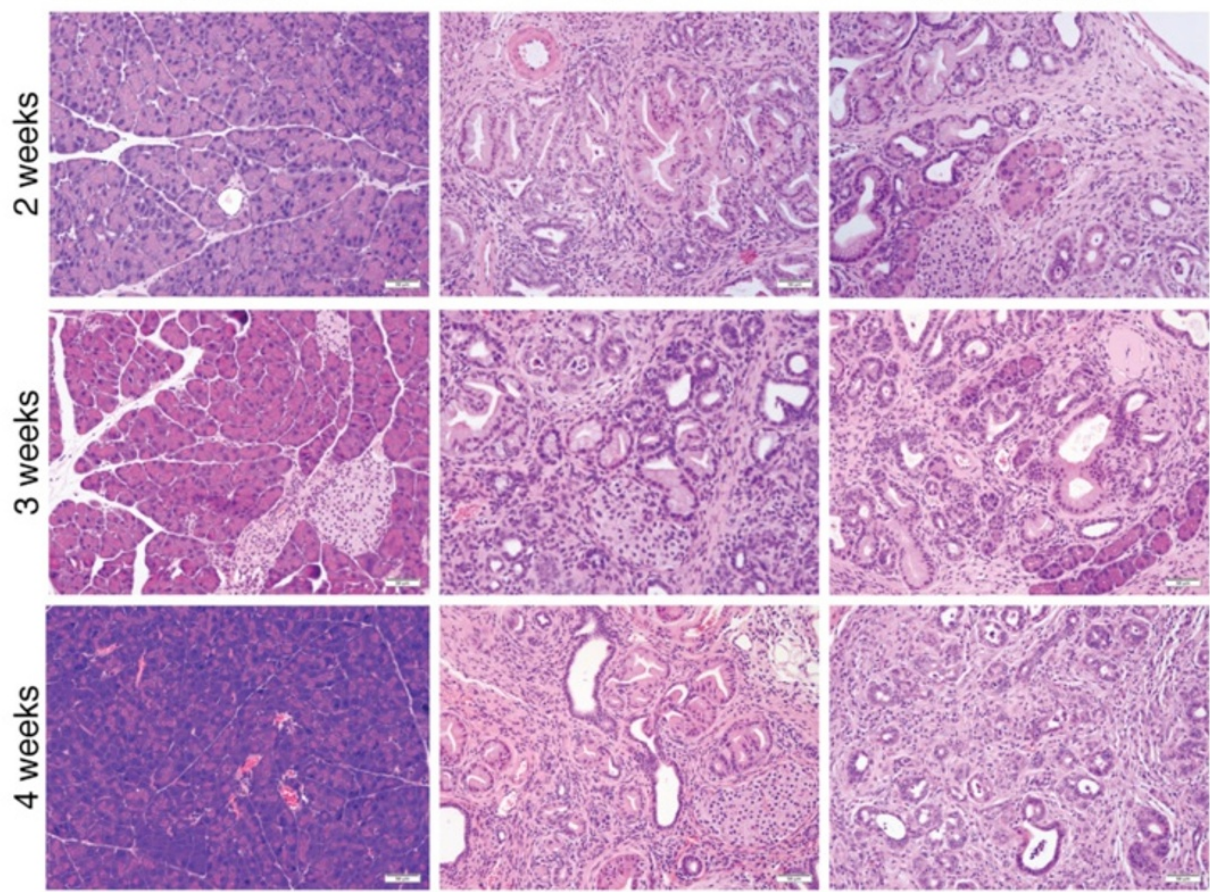

C

Histopathologic Analysis

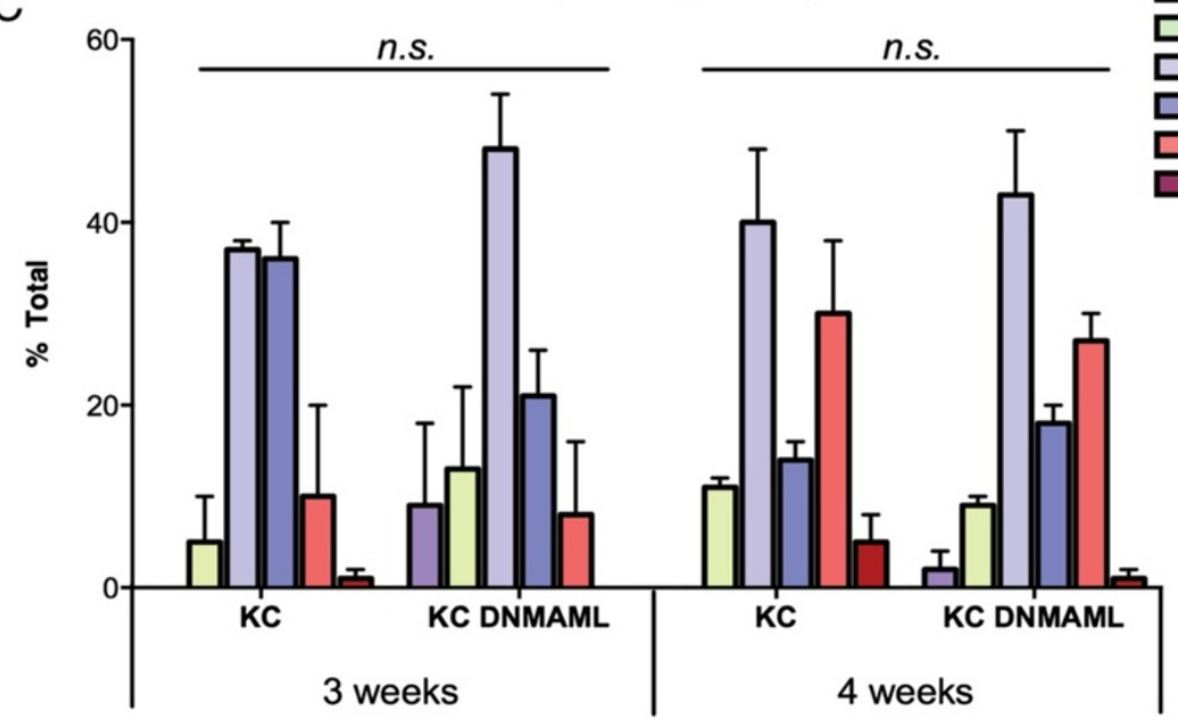

Figure 4 (See legend on next page.) 
(See figure on previous page.)

Figure 4 Effect of Notch inhibition during pancreatitis-induced PanIN formation - Preliminary data. (A) Age-matched wild type (control), p48Cre; LSL-Kras G12D (KC), and p48Cre;LSL-Kras G12D; Rosa ${ }^{\text {DNMAML-GFP/+ }}$ (KC;DNMAML) mice were administered intraperitoneal injections of caerulein, a cholecystokinin agonist, over the course of 48 hours. Pancreata was harvested and analyzed for PanIN development. ( $n=2$ mice/time point). (B) H\&E

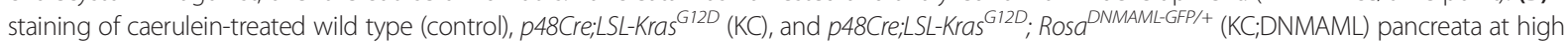
magnification (20x). ( $n=2$ mice/time point). (C) Quantification of pancreatic intraepithelial neoplasia (PanIN) at the indicated time points of age-matched p48Cre;LSL-Kras ${ }^{G 12 D}$ (KC), and p48Cre;LSL-Kras ${ }^{\text {G12D }}$; Rosa ${ }^{\text {DNMAML-GFP/+ }}$ (KC;DNMAML) mice ( $n=2$ mice/genotype). Color coding as follows: acini (dark purple), acinar-ductal metaplasia (ADM; green), PanIN1A (light blue), PanIN1B (blue), PanIN2 (red), PanIN3 (dark red). Data represents mean \pm SEM. n.s.: not statistically significant.

over the course of the first week after treatment. Then, the pancreas forms tissue-wide PanINs. The WT and KC cohorts in our experiment behaved as expected.. Similarly, KC;DNMAML developed PanINs, although they retained more acinar clusters 2 and 3 weeks after pancreatitis, compared to KC animals (Figure 4B,C). However, by 4 weeks after pancreatitis the two cohorts were indistinguishable. Based on our results from mice aging in absence of pancreatitis, this result might reflect progressive loss of Notch inhibition paralleling PanIN formation.

\section{Discussion}

The Notch signaling pathway plays an important role in embryonic development of the pancreas, in homeostasis of the adult pancreatic tissues, and it is reactivated during pancreatic cancer $[4,5,17,40-42]$. Several studies showed activation of Notch signaling as an early event in the development of pancreatic cancer [9-12], making inhibition of Notch signaling an attractive therapeutic target. Inhibition of Notch signaling in all cellular compartments by GSI treatment revealed that Notch is important for the initial development of PanINs and their progression to advanced PDA in mice [10]. A caveat to using GSIs is that they not only inhibit Notch signaling within the epithelium, but also in the tumor microenvironment (i.e. stellate cells, immune cells, fibroblasts). Thus, the ability of GSIs to globally inhibit Notch signaling, regardless of cell type, creates a challenge when teasing apart its role in epithelial cells. Mouse models that conditionally ablate Notch receptors in the pancreas epithelium demonstrated that Notch2, but not Notch3, is critical for PanIN initiation [16], although Notch3 is also upregulated during PanIN/PDA development $[9,10]$. A limitation of genetic inactivation of individual Notch receptors is that they have been shown to functionally compensate for each other [43]. Thus, none of these previous studies has addressed the role of epithelia-specific Notch signaling mediated by any of the Notch receptors.

In this study, we used an approach that allowed conditional, tissue-specific inhibition of canonical Notch signaling specifically in the pancreas epithelium (in a cell autonomous manner). Using a dominant negative form of Mastermind-like1 (DNMAML), we successfully inhibited transcriptional activation of Notch target genes, independent of Notch receptor input [21,22], in the pancreatic epithelium. DNMAML expression was previously shown to lead to impaired endocrine cell differentiation [44,45]. While a comprehensive characterization of the endocrine cells went beyond the scope of the current study, the mice presented with morphologically normal islets, probably reflecting differences in transgene expression levels or timing of expression. Our results showed delay, but not blockade, of PanIN formation. In part, this finding might be due to an escape mechanism allowing Notch signaling to be reactivated even in DNMAML expressing mice - either through transgene silencing, or possibly though sequestration of DNMAML away from the nucleus. Thus, epithelial Notch signaling appears to be required for the onset of PanIN formation. However, selection mechanisms lead to accumulation of cells with active Notch signaling. Our data do not address the potential role of Notch signaling in other cellular compartments, such as fibroblasts or the immune system. However, an initial analysis revealed little presence of Notch target components in fibroblasts. The status and potential role of Notch signaling in immune cells at different stages of cancer formation cannot be discounted and should be addressed in future studies.

\section{Conclusion}

Notch signaling is important for disease initiation early in PanIN development. However later in carcinogenesis, the role of Notch signaling in the tumor epithelium remains unclear. Future studies examining the role of Notch signaling in other cells within the tumor microenvironment (immune cells) may explain a purpose for maintaining Notch signaling throughout carcinogenesis. Notch inhibition is still an attractive target for neoadjuvant or prophylactic treatment in high-risk patients, but more work is needed.

\section{Additional file}

Additional file 1: Table S1. Antibodies. Table S2. Primer sequences for quantitative RT-PCR.

\section{Abbreviations}

PanIN: Pancreatic intraepithelial neoplasia; GSI: Gamma secretase inhibitor MAML: Mastermind-like; DNMAML: Dominant-negative form of Mastermindlike; ADM: Acinar-ductal metaplasia; PDA: Pancreatic ductal adenocarcinoma; NICD: Notch intracellular domain. 


\section{Competing interests}

The authors declare that they have no competing interests.

\section{Authors' contributions}

MMT carried out in vivo and in vitro experiments, participated in the design of the study and wrote the first draft of the manuscript. YZ carried out the histopathological analyses throughout study and edited the manuscript. EM carried out in vitro experiments and edited manuscript. KTK performed quantification of DNMAML expression (GFP staining). IM participated in the design of the study and critically revised the manuscript. MPdM conceived the study, participated in the design of the study, and wrote the manuscript. All authors read and approved the final manuscript.

\section{Acknowledgements}

We thank Anj Dlugosz (University of Michigan, Ann Arbor, MI) for scientific discussion and insightful comments. For the Hes1 antibody and staining protocol we thank Ben Stanger (University of Pennsylvania, Philadelphia, PA, USA).

\section{Grant support}

This project was supported by a Pancreatic Cancer Action Network (PanCan)/American Association for Cancer Research (AACR) Career Development Award (09-20-25-PASC), the University of Michigan Biological Scholar Program, the University of Michigan Cancer Center, and NCl-1R01CA151588-01. Esha Mathew was supported by a University of Michigan Program in Cellular and Molecular Biology training Grant (NIH T32 GM007315) and a University of Michigan Gastrointestinal Training Grant (NIH T32 DK094775).

\section{Author details}

${ }^{1}$ Department of Surgery, 1500 E Medical Center Drive, Ann Arbor, Michigan 48109-5936, USA. ${ }^{2}$ Cell and Molecular Biology Program, University of Michigan, 2966 Taubman Medical Library, Ann Arbor, MI 48109-0619, USA. ${ }^{3}$ Life Science Institute, University of Michigan, 210 Washtenaw Avenue, Ann Arbor, MI 48109-2216, USA. ${ }^{4}$ Department of Cell and Developmental Biology, University of Michigan, 3059 A. Alfred Taubman Biomedical Science Research Building, 109 Zina Pitcher Place, Ann Arbor, MI 48109-2200, USA.

Received: 13 May 2014 Accepted: 13 November 2014

Published: 22 November 2014

\section{References}

1. Hariharan D, Saied A, Kocher HM: Analysis of mortality rates for pancreatic cancer across the world. HPB (Oxford) 2008, 10:58-62.

2. Siegel R, Naishadham D, Jemal A: Cancer statistics, 2013. CA Cancer J Clin 2013, 63:11-30.

3. Hruban RH, Goggins M, Parsons J, Kern SE: Progression model for pancreatic cancer. Clin Cancer Res 2000, 6:2969-2972.

4. Hingorani SR, Petricoin EF, Maitra A, Rajapakse V, King C, Jacobetz MA, Ross S, Conrads TP, Veenstra TD, Hitt BA, Kawaguchi Y, Johann D, Liotta LA, Crawford HC, Putt ME, Jacks T, Wright CV, Hruban RH, Lowy AM, Tuveson DA: Preinvasive and invasive ductal pancreatic cancer and its early detection in the mouse. Cancer Cell 2003, 4:437-450

5. Di Magliano MP, Sekine S, Ermilov A, Ferris J, Dlugosz AA, Hebrok M: Hedgehog/Ras interactions regulate early stages of pancreatic cancer. Genes Dev 2006, 20:3161-3173.

6. Collins MA, Bednar F, Zhang YQ, Brisset JC, Galban S, Galban CJ, Rakshit S, Flannagan KS, Adsay NV, Di Magliano MP: Oncogenic Kras is required for both the initiation and maintenance of pancreatic cancer in mice. J Clin Invest 2012, 122:639-653.

7. Bardeesy N, DePinho RA: Pancreatic cancer biology and genetics. Nat Rev Cancer 2002, 2:897-909.

8. Di Magliano MP, Biankin AV, Heiser PW, Cano DA, Gutierrez PJA, Deramaudt T, Segara D, Dawson AC, Kench JG, Henshall SM, Sutherland RL, Dlugosz A, Rustgi AK, Hebrok M: Common activation of canonical wnt signaling in pancreatic adenocarcinoma. Plos One 2007, 2:e1155.

9. Miyamoto Y, Maitra A, Ghosh B, Zechner U, Argani P, lacobuzio-Donahue CA, Sriuranpong V, Iso T, Meszoely IM, Wolfe MS, Hruban RH, Ball DW, Schmid RM, Leach SD: Notch mediates TGF alpha-induced changes in epithelial differentiation during pancreatic tumorigenesis. Cancer Cell 2003, 3:565-576.
10. Plentz R, Park JS, Rhim AD, Abravanel D, Hezel AF, Sharma SV, Gurumurthy S, Deshpande V, Kenific C, Settleman J, Majumder PK, Stanger BZ, Bardeesy $\mathrm{N}$ : Inhibition of gamma-secretase activity inhibits tumor progression in a mouse model of pancreatic ductal adenocarcinoma. Gastroenterology 2009, 136:1741-1749.

11. Wang Z, Li Y, Kong D, Banerjee S, Ahmad A, Azmi AS, Ali S, Abbruzzese JL, Gallick GE, Sarkar FH: Acquisition of epithelial-mesenchymal transition phenotype of gemcitabine-resistant pancreatic cancer cells is linked with activation of the notch signaling pathway. Cancer Res 2009, 69:2400-2407.

12. Mullendore ME, Koorstra JB, Li YM, Offerhaus GJ, Fan X, Henderson CM, Matsui W, Eberhart CG, Maitra A, Feldmann G: Ligand-dependent notch signaling is involved in tumor initiation and tumor maintenance in pancreatic cancer. Clin Cancer Res 2009, 15:2291-2301.

13. Bao B, Wang Z, Ali S, Kong D, Li Y, Ahmad A, Banerjee S, Azmi AS, Miele L, Sarkar FH: Notch-1 induces epithelial-mesenchymal transition consistent with cancer stem cell phenotype in pancreatic cancer cells. Cancer Lett 2011, 307:26-36.

14. Hemming ML, Elias JE, Gygi SP, Selkoe DJ: Proteomic profiling of gamma-secretase substrates and mapping of substrate requirements. PLOS Biol 2008, 6:e257.

15. Hanlon L, Avila JL, Demarest RM, Troutman S, Allen M, Ratti F, Rustgi AK, Stanger BZ, Radtke F, Adsay V, Long F, Capobianco AJ, Kissil JL: Notch1 functions as a tumor suppressor in a model of K-ras-induced pancreatic ductal adenocarcinoma. Cancer Res 2010, 70:4280-4286.

16. Mazur PK, Einwachter H, Lee M, Sipos B, Nakhai H, Rad R, Zimber-Strobl U, Strobl LJ, Radtke F, Kloppel G, Schmid RM, Siveke JT: Notch2 is required for progression of pancreatic intraepithelial neoplasia and development of pancreatic ductal adenocarcinoma. Proc Natl Acad Sci U S A 2010, 107:13438-13443.

17. Nakhai H, Siveke JT, Klein B, Mendoza-Torres L, Mazur PK, Algul H, Radtke F, Strobl L, Zimber-Strobl U, Schmid RM: Conditional ablation of Notch signaling in pancreatic development. Development 2008, 135:2757-2765.

18. Wu L, Sun T, Kobayashi K, Gao P, Griffin JD: Identification of a family of mastermind-like transcriptional coactivators for mammalian notch receptors. Mol Cell Biol 2002, 22:7688-7700.

19. Kawaguchi Y, Cooper B, Gannon M, Ray M, MacDonald RJ, Wright CV: The role of the transcriptional regulator Ptf1a in converting intestinal to pancreatic progenitors. Nat Genet 2002, 32:128-134.

20. Tuveson DA, Shaw AT, Willis NA, Silver DP, Jackson EL, Chang S, Mercer KL, Grochow R, Hock H, Crowley D, Hingorani SR, Zaks T, King C, Jacobetz MA, Wang L, Bronson RT, Orkin SH, DePinho RA, Jacks T: Endogenous oncogenic K-ras(G12D) stimulates proliferation and widespread neoplastic and developmental defects. Cancer Cell 2004, 5:375-387.

21. Maillard I, Koch U, Dumortier A, Shestova O, Xu L, Sai H, Pross SE, Aster JC, Bhandoola A, Radtke F, Pear WS: Canonical notch signaling is dispensable for the maintenance of adult hematopoietic stem cells. Cell Stem Cell 2008, 2:356-366.

22. Maillard I, Tu L, Sambandam A, Yashiro-Ohtani Y, Millholland J, Keeshan K, Shestova O, Xu L, Bhandoola A, Pear WS: The requirement for Notch signaling at the beta-selection checkpoint in vivo is absolute and independent of the pre-T cell receptor. J Exp Med 2006, 203:2239-2245.

23. Truett GE, Heeger P, Mynatt RL, Truett AA, Walker JA, Warman ML: Preparation of PCR-quality mouse genomic DNA with hot sodium hydroxide and tris (HotSHOT). Biotechniques 2000, 29:52-54.

24. Morris JP, Cano DA, Sekine S, Wang SC, Hebrok M: Beta-catenin blocks Kras-dependent reprogramming of acini into pancreatic cancer precursor lesions in mice. J Clin Invest 2010, 120:508-520.

25. Kojima K, Vickers SM, Adsay NV, Jhala NC, Kim HG, Schoeb TR, Grizzle WE, Klug CA: Inactivation of Smad4 accelerates Kras(G12D)-mediated pancreatic neoplasia. Cancer Res 2007, 67:8121-8130.

26. Hruban RH, Rustgi AK, Brentnall TA, Tempero MA, Wright CV, Tuveson DA: Pancreatic cancer in mice and man: the penn workshop 2004. Cancer Res 2006, 66:14-17.

27. Mumm JS, Kopan R: Notch signaling: from the outside in. Dev Biol 2000, 228:151-165.

28. Jouve C, Palmeirim I, Henrique D, Beckers J, Gossler A, Ish-Horowicz D, Pourquie O: Notch signalling is required for cyclic expression of the hairy-like gene HES1 in the presomitic mesoderm. Development 2000, 127:1421-1429. 
29. Steidl C, Leimeister C, Klamt B, Maier M, Nanda I, Dixon M, Clarke R, Schmid M, Gessler M: Characterization of the human and mouse HEY1, HEY2, and HEYL genes: cloning, mapping, and mutation screening of a new bHLH gene family. Genomics 2000, 66:195-203.

30. Maier MM, Gessler M: Comparative analysis of the human and mouse hey1 promoter: hey genes are new Notch target genes. Biochem Biophys Res Commun 2000, 275:652-660.

31. Scholzen T, Gerdes J: The Ki-67 protein: from the known and the unknown. J Cell Physiol 2000, 182:311-322.

32. Berman DM, Karhadkar SS, Maitra A, Montes De Oca R, Gerstenblith MR, Briggs K, Parker AR, Shimada Y, Eshleman JR, Watkins DN, Beachy PA: Widespread requirement for Hedgehog ligand stimulation in growth of digestive tract tumours. Nature 2003, 425:846-851.

33. Yauch RL, Gould SE, Scales SJ, Tang T, Tian H, Ahn CP, Marshall D, Fu L, Januario T, Kallop D, Nannini-Pepe M, Kotkow K, Marsters JC, Rubin LL, de Sauvage FJ: A paracrine requirement for hedgehog signalling in cancer. Nature 2008, 455:406-410.

34. Lucero OM, Dawson DW, Moon RT, Chien AJ: A re-evaluation of the "oncogenic" nature of Wnt/beta-catenin signaling in melanoma and other cancers. Curr Oncol Rep 2010, 12:314-318.

35. Zhang Y, Morris JP, Yan W, Schofield HK, Gurney A, Simeone DM, Millar SE, Hoey T, Hebrok M, Pasca Di Magliano M: Canonical wnt signaling is required for pancreatic carcinogenesis. Cancer Res 2013, 73:4909-4922.

36. Mills $L D$, Zhang Y, Marler RJ, Herreros-Villanueva M, Zhang L, Almada LL, Couch F, Wetmore C, Pasca Di Magliano M, Fernandez-Zapico ME: Loss of the transcription factor GLI1 identifies a signaling network in the tumor microenvironment mediating KRAS oncogene-induced transformation. J Biol Chem 2013, 288:11786-11794

37. Guerra C, Collado M, Navas C, Schuhmacher AJ, Hernandez-Porras I, Canamero M, Rodriguez-Justo M, Serrano M, Barbacid M: Pancreatitisinduced inflammation contributes to pancreatic cancer by inhibiting oncogene-induced senescence. Cancer Cell 2011, 19:728-739.

38. Guerra C, Schuhmacher AJ, Canamero M, Grippo PJ, Verdaguer L, Perez-Gallego L, Dubus P, Sandgren EP, Barbacid M: Chronic pancreatitis is essential for induction of pancreatic ductal adenocarcinoma by K-Ras oncogenes in adult mice. Cancer Cell 2007, 11:291-302.

39. Carriere C, Young AL, Gunn JR, Longnecker DS, Korc M: Acute pancreatitis accelerates initiation and progression to pancreatic cancer in mice expressing oncogenic Kras in the nestin cell lineage. PLoS One 2011, 6:e27725.

40. Murtaugh LC, Stanger BZ, Kwan KM, Melton DA: Notch signaling controls multiple steps of pancreatic differentiation. Proc Natl Acad Sci U S A 2003, 100:14920-14925.

41. Rooman I, De Medts N, Baeyens L, Lardon J, De Breuck S, Heimberg H, Bouwens $L$ : Expression of the Notch signaling pathway and effect on exocrine cell proliferation in adult rat pancreas. Am J Pathol 2006, 169:1206-1214.

42. Siveke JT, Lubeseder-Martellato C, Lee M, Mazur PK, Nakhai H, Radtke F, Schmid RM: Notch signaling is required for exocrine regeneration after acute pancreatitis. Gastroenterology 2008, 134:544-555.

43. Kitamoto T, Takahashi K, Takimoto H, Tomizuka K, Hayasaka M, Tabira T, Hanaoka K: Functional redundancy of the Notch gene family during mouse embryogenesis: analysis of Notch gene expression in Notch3-deficient mice. Biochem Biophys Res Commun 2005, 331:1154-1162.

44. Afelik S, Qu X, Hasrouni E, Bukys MA, Deering T, Nieuwoudt S, Rogers W, Macdonald RJ, Jensen J: Notch-mediated patterning and cell fate allocation of pancreatic progenitor cells. Development 2012, 139:1744-1753.

45. Horn S, Kobberup S, Jorgensen MC, Kalisz M, Klein T, Kageyama R, Gegg M, Lickert H, Lindner J, Magnuson MA, Kong YY, Serup P, Ahnfelt-Rønne J, Jensen JN: Mind bomb 1 is required for pancreatic beta-cell formation. Proc Natl Acad Sci U S A 2012, 109:7356-7361.

\section{doi:10.1186/1471-2407-14-862}

Cite this article as: Thomas et al: Epithelial Notch signaling is a limiting step for pancreatic carcinogenesis. BMC Cancer 2014 14:862.

\section{Submit your next manuscript to BioMed Central and take full advantage of:}

- Convenient online submission

- Thorough peer review

- No space constraints or color figure charges

- Immediate publication on acceptance

- Inclusion in PubMed, CAS, Scopus and Google Scholar

- Research which is freely available for redistribution 